\title{
Patient Anxiety and Conscious Surgery
}

A bstract

The amount of surgery undertaken on the conscious patient is increasing. However, many patients are anxious and resistant to such surgery. Patients $(n=214)$ were surveyed to determine their related apprehensions. Being awake, feeling or seeing the body cut open and experiencing pain all increased anxiety. The potential for insufficient information provision was also a source of concern. Formal management of intra-operative apprehension may help limit anxiety and expel apparent misapprehensions.

B a c kground

The aim of this study was to uncover aspects patients find anxiety provoking whilst undergoing surgery with local/ regional anaesthesia. This was required as the number of surgical procedures now possible in day and short stay surgery is increasing (Howat et al 2006, Jacquet et al 2006) together with the number of surgical procedures possible using local or regional anaesthesia (Zanchetta \& Bernstein 2004, Raeder 2006, Ternisien et al 2006, Delikoukos \& Gikas 2007, Weidmann \& Grundy 2008).

Operating theatre design and function has traditionally been associated with the care of the unconscious patient (Essex-Lopresti 1999) although with the envisaged decline in the number of patients undergoing general anaesthesia, care of the conscious patient will become a more central feature of theatre nursing (Chit Ying et al 2001). It has been suggested that arriving at the theatre door (Kennedy et al 1992) together with the experience of the theatre environment, that is, the sounds of the operating room (Jakobsen \& Fagermoen 2005), monitor alarms, surgical instruments being unpacked (Hankela \& Kiikkala 1996), narrowness of the table and low temperature, all give rise to increased anxiety during surgery under local/ regional anaesthesia (Chit Ying et al 2001). Aspects associated with the actual surgery such as the surgeon's touch (De Andres et al 1995), possible repeated needle punctures 
(Gajraj \& Sidawi 1993, Koscielniak-Nielsen et al 2002, Matthey et al 2004) or potentially insufficient use of local anaesthesia (Callesen et al 2001) have also given rise to increased apprehension.

As a result of such concerns the majority of patients prefer general anaesthesia to local anaesthesia (Shevde \& Panagopoulos 1991, Papanikolaou et al 1994). Again, common reasons for not wanting local anaesthesia were the experience of injections, dislike of being awake in the theatre and the wait between administration of anaesthesia and commencement of surgery (Gajraj et al 1995, Rees \& Tagoe 2002). However, it is suggested that such experiences can be improved by providing explanations and enhancing the theatre environment (Gnanalingham \& Budhoo 1998, Jakobsen \& Fagermoen 2005). For example, Whittle et al (2005) suggested a comfortable operating table, keeping the patient warm, a dedicated person for patient communication and minimising pain and discomfort.

The potential pain associated with the injections, restricted communication and the uncomfortable theatre environment (temperature, noise and narrow table) therefore appear formidable barriers for patients when considering local/ regional anaesthesia. As the operating theatre has historically been linked with the unconscious patient, the peri-operative practices associated with the conscious patient may require greater scrutiny. A study exploring the psychological experience of the 'awake' patient in theatre was therefore deemed necessary. The research question was therefore 'What environmental factors influence anxiety for the 'awake' adult patient undergoing, elective day surgery'.

Method

A questionnaire was constructed and utilised within a larger study examining the wider issues of anxiety associated with the clinical environment, hospital personnel and general and local/ regional anaesthesia $(n=673)$. However, this paper will only consider the questions relating to the effect of the environment on patient anxiety 
when experiencing local/ regional anaesthesia (Table 1). The questionnaire was complied using evidence gained from the literature together with previously undertaken studies within this field (Mitchell 1997, Mitchell 2000, Mitchell 2006). Moreover, a pilot study was undertaken utilising the first $10 \%$ of respondents. This resulted in minor amendments to the questionnaire prior to continuation of data collection. All items on the questionnaire were structured using a Likert Scale format, for example, very anxious, a little anxious, made no difference, a little calm, very calm or never thought about it.

TABLE 1

INTRA-OPERATIVE APPREHENSION.

\section{Intra-operative apprehension}

1. How would your anaesthetist explaining your anaesthetic before going to theatre affect your anxiety?

2. How would a nurse explaining your anaesthetic on the ward before going to theatre affect anxiety?

3. How would being told how long your anaesthetic will last affect your anxiety?

4. How would being told how soon the numbness will take to wear off affect your anxiety?

5. How would being told how soon you will be able to eat and drink again affect your anxiety?

6. How would always being told what was to happen next affect your anxiety?

7. How did the thought of possibly needing more than one injection to numb your skin affect your anxiety?

8. How did the thought of possibly needing a drip (intravenous infusion) affect your anxiety?

9. How did the thought of being awake during the operation affect your anxiety?

10. How did the thought of possibly hearing what the doctors and nurses were saying in theatre affect your anxiety?

11. How did the thought of possibly feeling what the surgeon was doing in theatre affect your anxiety?

12. How did the thought of possibly seeing your body 'cut open' affect your anxiety?

13. How did the thought of the operation possibly being more painful because you were awake affect your anxiety?

14. How did the thought of the numbness possibly wearing off before the operation was finished affect your anxiety?

15. How did the thought of possibly feeling 'closed in' (claustrophobic) during the operation affect your anxiety?

16. How did the thought of the pain possibly being worse afterwards because only a part of your body was being made numb affect your anxiety?

Data were collected from four public Day Surgery Units over a two-year period (2005 - 2007). All four Day Surgery Units were situated within a large City in the Northwest of England and all surgeons, anaesthetists and nursing staff gave their consent to the study prior to local Ethics Committee approval. A convenience sample 
of patients meeting the inclusion criteria (non life-threatening, intermediate surgery, no history of chronic physical or mental health, English speaking, 18 years upwards and not undergoing ophthalmic or dental surgery) were invited to participate. (ophthalmic and dental patients were excluded as such patients were deemed to possibly experience additional anxieties resulting from the type of surgery). The staff within each Day Surgery Unit invited patients on the day of surgery (who met the inclusion criteria) to take home the questionnaire. The questionnaires were to be completed at home by the patients $24-48$ hours after surgery and return by mail in the pre-paid envelope provided.

Results

Two-hundred and fourteen patients undergoing surgery with local/ regional anaesthesia completed this part of the survey. Patients underwent a variety of surgical procedures with General Surgery (hernia repair, cholecystectomy) (37\%) and Orthopaedic Surgery (35\%) being the most frequent. The number of patients experiencing a degree of anxiety on the day of surgery was $77 \%$ (Graph 1). Many patients experienced anxiety resulting from the thought of being awake (60\%), possibly feeling the surgeon (60\%), potentially seeing their body cut open (47\%), the thought of the numbness wearing off too quickly (53\%) or the thought of local/ regional anaesthesia being more painful (61\%). Patients stated it would be calming if the nurse explained events (54\%), the anaesthetist explained events (64\%) and they were informed of what would happen next, that is, the sequential order of events (56\%) (Mitchell 2005).

In addition to the descriptive statistics, further scrutiny of the data was undertaken utilising factor analysis. Exploratory factor analysis seeks to summarise all the data uncovered and reduce the findings into smaller coherent portions. Following factor analysis, two components or factors were established and referred to as 'Anaesthetic Information Provision' and 'Intra-operative Apprehension'. Questions relating to the 
nurse and anaesthetist providing information and explanations (Table 2) were given the overall title of 'anaesthetic information provision' as during factor analysis such aspects were all positively related. Similarly, questions relating to being awake, seeing, hearing, feeling (Table 3) were given the overall title of 'intra-operative apprehension' as again during factor analysis such aspects were positively.

\section{GRAPH 1}

ANXIETY ON DAY OF SURGERY $(n=210)$.

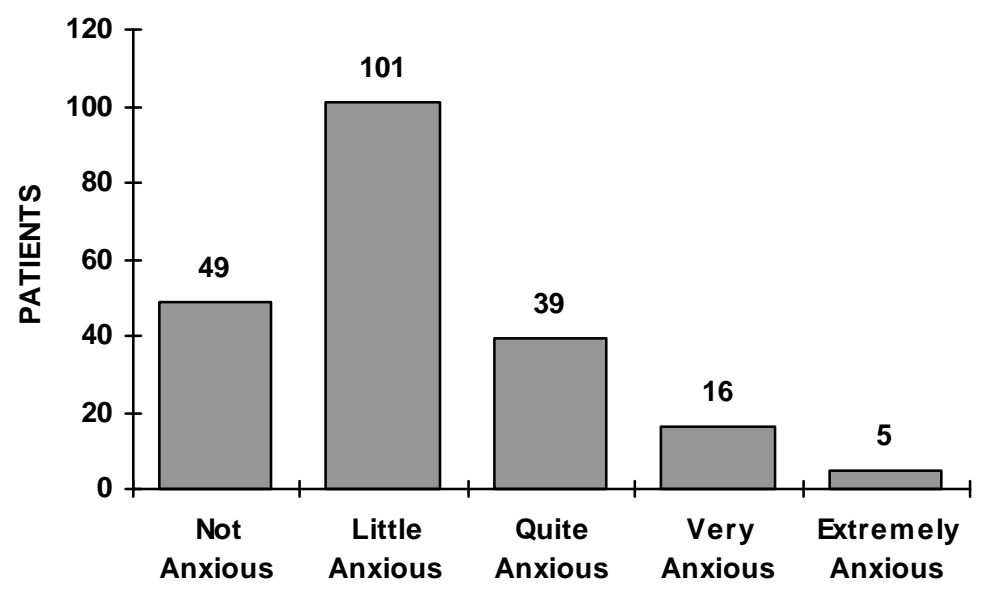

These two new variables of 'anaesthetic information provision' and 'intra-operative apprehension' were then entered into a multiple regression analysis. Multiple regression analysis is employed to help determine if an overall level of anxiety can be predicted by the two new variables created during factor analysis (anaesthetic information provision and intra-operative apprehension). This indeed was the case and 'anaesthetic information provision' together with 'intra-operative apprehension' were deemed to be accurate predictors of increased anxiety on the day of surgery (Mitchell 2008). Therefore, it can be confidently stated that increased patient anxiety prior to conscious day surgery is directly related to the issues collectively referred to here as 'anaesthetic information provision.' and 'intra-operative apprehension' (Tables 2 \& 3). 
TABLE 2

ANAESTHETIC INFORMATION PROVISION.

\begin{tabular}{|l|}
\hline \multicolumn{1}{|c|}{ Anaesthetic Information Provision } \\
\hline Anaesthetist explaining the anaesthetic \\
Nurse explaining the anaesthetic \\
Informed how long anaesthetic will last \\
Informed how long numbness will last \\
\hline
\end{tabular}

TABLE 3

INTRA-OPERTAIVE APPREHENSION.

\begin{tabular}{|l|}
\hline \multicolumn{1}{|c|}{ Intra-operative Apprehension } \\
\hline Thought of needing more than 1 injection \\
Thought of needing intravenous infusion \\
Thought of being awake during operation \\
Thought of hearing during operation \\
Thought of feeling surgeon during operation \\
Thought of seeing body cut open \\
Thought of RA/ LA being more painful \\
Nurse explaining the anaesthetic. \\
\hline
\end{tabular}

D i s c us i o n

Firstly, a number of limitations to the study may have influenced the results. Data collection was undertaken using a questionnaire that had not been previously utilised or validated. Therefore, questions could have been included that participants did not find relevant and other more pertinent items may have been excluded. Participants may therefore not have been able to express all their views. However, the questionnaire was rigorously constructed from the available literature and previous studies (Mitchell 2005). Secondly, only 41\% of participants responded which could have limited the information obtained. However, such a response rate is not uncommon in postal surveys, especially with a sample population who quickly resume their 'normal' lifestyle (Clark et al 2002).

The research question was 'What environmental factors influence anxiety for the 'awake' adult patient undergoing, elective day surgery'. Although patients were undergoing local or regional anaesthesia, 77\% experienced some degree of anxiety (Graph 1). Clearly, therefore, the majority of patients experiencing local or regional anaesthesia were somewhat anxious. Apprehension arose largely in two distinct areas referred to here as anaesthetic information provision (Table 2) and intraoperative apprehension (Table 3). These two aspects were derived from a combination of exploratory factor analysis and multiple regression analysis.

The first distinct area of patient anxiety concerned anaesthetic provision information. For example, being informed of how long the anaesthetic will last and 
how long the local or regional anaesthetic would take to dissipate (Table 2). Other studies have also demonstrated the value of this kind of pre-operative information provision (Tong et al 1997, Jakobsen \& Fagermoen 2005) although frequently such information may, in the initial stages of treatment, become marginalised as the patient remains focused upon the impact of the actual surgery (Parroy et al 2003). However, as the date of surgery approaches the patient may begin to consider the wider aspects of surgery, that is, the experiences of local or regional anaesthesia. Gradually patients realise, for example, that they may not be able to move their anaesthetised limb in the usual manner and may therefore wish to have a greater understanding of their anaesthetic (Bhattarai et al 2005, Mauleon et al 2007). This may necessitate a more formal approach to information provision in regard to the use of local or regional anaesthesia (Lack et al 2003). Previous studies have revealed that being informed in advance of anaesthesia has aided the more effective management of anxiety (Lee et al 2003, Johansson et al 2005), that is, the sequential order of events being explained and patients being provided, where possible, with some choice (McKenna 1997, Gillies \& Baldwin 2001, Ward et al 2007). Also, possible fears relating to the use of local or regional anaesthesia can be explored and common misapprehensions discussed (Mauleon et al 2007, Rudolfsson et al 2007). Moreover, during this period patients can be informed of the safe and effectiveness of the drugs employed (Royal College of Anaesthetists and Association of Anaesthetists Great Britain and Ireland 2003).

The second distinct area of patient anxiety concerned misconceptions associated with intra-operative events, that is, being awake and thereby possibly being susceptible to seeing, feeling or hearing the surgical procedure (Table 3). Similar findings have also been revealed by Costa (2001) when questioning day surgery patients. Patients were apprehensive about their anaesthetic because of the fear of dying, loosing physical and/ or emotional control or the possibility of seeing their body being cut open. Other studies have also revealed similar findings concerning the possibility of feeling the surgeon (De Andres et al 1995), viewing surgical events, hearing discussions in the operating theatre (Gajraj et al 1995) or experiencing an increased level of pain (Gajraj \& Sidawi 1993, Koscielniak-Nielsen et al 2002). Although many of these apprehensions are unfounded, the patients in the present study were clearly unaware of this and therefore quite apprehensive. Indeed, Matthey et al (2004) suggests that the public's fears and perceptions regarding regional anaesthesia are greatly distorted. 
Clinical Recommendations

Communication with the nursing staff and anaesthetist prior to the induction of anaesthesia was viewed by patients as beneficial in that it helped to reduce the anxiety associated with conscious surgery. This has been suggested as an essential element of intra-operative care (Leinonen et al 1996, Leinonen \& Leino-Kilpi 1999, Rudolfsson et al 2003). However, over three-quarters of the patients scheduled for local or regional anaesthesia in the present study had little knowledge regarding intra-operative events.

Patient interaction with the nurses and anaesthetist prior to surgery is vital as they frequently seek answers to a number of questions (Lithner \& Zilling 2000, Kindler et al 2005). Furthermore, the period immediately prior to surgery may be the first time the patient has had the opportunity to meet with their anaesthetist (Parroy et al 2003). During this period, patients' perceptions of the safe and effective use of local/ regional anaesthesia can again be discussed (Lee \& Gin 2005). Moreover, discussing safety and the potential risks are an essential part of informing patients about their anaesthesia (Lack et al 2003). This is also an opportunity to help dispel misapprehensions and limit catastrophising thoughts (De Andres et al 1995, Gajraj et al 1995) (Table 4).

\section{TABLE 4}

Peri-OPerative information Provision

\begin{tabular}{|c|l|}
\cline { 2 - 3 } \multicolumn{1}{c|}{} & \multicolumn{1}{c|}{ Intervention } \\
\hline Anaesthetic & $\begin{array}{l}\text { Prior to the day of surgery information provided } \\
\text { regarding anaesthesia to help dispel } \\
\text { misapprehensions and limit catastrophising } \\
\text { thoughts. } \\
\text { Explore possible common anxiety provoking } \\
\text { issues associated with surgery on the conscious } \\
\text { self such as being awake, seeing, hearing, } \\
\text { feeling. } \\
\text { Emphasis upon comfort, safety and effective } \\
\text { anaesthesia. }\end{array}$ \\
\hline
\end{tabular}

The lack of pre-operative information provision clearly lead to much anxiety and was the catalyst for numerous intrusive catastrophising thoughts. Helping to reduce such uncertainty and minimising the impact of the human physiological stressresponse is one of the foundations upon which modern elective surgery is being built (Wilmore 2002). Patients should therefore be prompted regularly regarding their comfort, safety, level and source of anxiety immediately prior to, and during, surgery (Nijkamp et al 2002). Controlled local/ regional anaesthesia can be emphasized together with the effectiveness of the drugs employed. Distraction techniques 
(Hankela \& Kiikkala 1996, Diette et al 2003, Gilmartin \& Wright 2007) and the use of intra-operative music (Chit Ying et al 2001, Yung et al 2003) have also been suggested to aid intra-operative apprehension. A number of studies have further suggested the need for a dedicated nurse to be free to interact with the patient throughout the intra-operative period (McCarthy et al 2004, Marran 2005). Respect and attention to intra-operative physical comfort have been strongly recommended (Hadjistavropoulos et al 2001) and the continued development of a 'conscious patient friendly' theatre environment (Lehrner et al 2000, Stirling 2006, Lorenz 2007, Stirling et al 2007) is vital if more patients are to experience (or be encourage to experience) local and regional anaesthesia (Hankela \& Kiikkala 1996) (Table 5).

\section{TABLE 5}

INTRA-OPERATIVE INTERVENTION

\begin{tabular}{|c|c|}
\hline & Intervention \\
\hline Intra-operative & $\begin{array}{l}\text { Interaction with patient immediately prior to } \\
\text { anaesthesia. } \\
\text { Regular prompting regarding, comfort, temperature, } \\
\text { anxiety, catastrophising thoughts, experience of } \\
\text { pain or feeling surgeon. } \\
\text { Emphasize anaesthesia will not 'wear off' too soon } \\
\text { although immediate action will be taken in this } \\
\text { unlikely event. } \\
\text { Simple methods of distraction (if desired) e.g. } \\
\text { talking or music via headphones. } \\
\text { Dedicated nurse to interact throughout surgery } \\
\text { regarding comfort, temperature, physical } \\
\text { environment and potential noise e.g. explain noises } \\
\text { such as monitors bleeping. }\end{array}$ \\
\hline
\end{tabular}

Conclusion

The aim of the study was to uncover aspects patients find anxiety provoking whilst undergoing surgery with local/ regional anaesthesia. Two areas were identified which gave rise to considerable anxiety for the majority of patients - anaesthetic information provision and intra-operative apprehension. Therefore, it can be confidently stated that anxiety prior to local/ regional anaesthesia will be associated with a lack of accurate information (length of anaesthesia, period of numbness) and misconceptions regarding intra-operative events (feeling, seeing, hearing surgery). It is recommended that communication takes place prior to the day of surgery to help explore and dispel misapprehensions and emphasize safe, controlled anaesthesia. In addition, the utilisation of a dedicated intra-operative nurse and development of a 'patient friendly' theatre environment must be pursued. Future studies may wish to investigate a comparison between use of a dedicated nurse, distracting techniques, 
intra-operative music (via headphones) and 'conscious patient friendly' theatre environments.

\section{References}

Bhattarai B, Rahman TR, Sah BP and Singh SN 2005 Central neural blocks: a quality assessment of anaesthesia in gynaecological surgeries. Nepal Medical College Journal 7 (2) 93 - 96

Callesen T, Bech K and Kehlet H 2001 One-thousand consecutive inguinal hernia repairs under unmonitored local anesthesia. Anesthesia and Analgesia 93 (6) 1373 - 1376

Chit Ying L, Levy V, Shan CO, Wing Hung T and Kit Wah W 2001 A qualitative study of the perceptions of Hong Kong Chinese women during caesarean section under regional anaesthesia Midwifery 17 (2) 115 - 122

Clark K, Voase R, Cato G, Fletcher IR and Thomson PJ 2002 Patients' experience of oral day case surgery: feedback from a nurse-led pre-admission clinic Ambulatory Surgery 8 (2) 93 - 96

Costa MJ 2001 The lived perioperative experience of ambulatory surgery patients American Operating Room Nurses' Journal 74 (6) 874 - 881

De Andres J, Valia JC, Gil A and Bolinches R 1995 Predictors of patient satisfaction with regional anesthesia. Regional Anesthesia 20 (6) 498 - 505

Delikoukos S and Gikas D 2007 The role of local anaesthesia in ambulatory anal surgery Ambulatory Surgery 13 (3) 1 - 10

Diette GB, Lechtzin N, Haponik E, Devrotes A and Rubin HR 2003 Distraction therapy with nature sights and sounds reduces pain during flexible bronchoscopy Chest 123 (3) 941 - 948

Essex-Lopresti M 1999 Operating theatre design Lancet 353 (9157) 1007- 1010

Gajraj N and Sidawi E 1993 How painful is insertion of a spinal needle? Anesthesia and Analgesia 76 (6) 1370

Gajraj NM, Sharma SK, Souter AJ, Pole Y and Sidawi JE 1995 A survey of obstetric patients who refuse regional anaesthesia Anaesthesia 50 (8) 740 - 741

Gillies MAM and Baldwin FJ 2001 Do patient information booklets increase peri-operative anxiety? European Journal of Anaesthesiology 18 (9) 620 - 622

Gilmartin J and Wright K 2007 The nurse's role in day surgery: A literature review. International Nursing Review 54 (2) 183 - 190

Gnanalingham KK and Budhoo M 1998 Day case hernia repair under local versus general anaesthetic: Patient preferences Ambulatory Surgery 6 (4) 227 - 229

Hadjistavropoulos HD, Dobson J and Boisvert JA 2001 Information provision, patient involvement, and emotional support: prospective areas for improving anesthetic care Canadian Journal of Anaesthesia 48 (9) 864 - 870

Hankela S and Kiikkala I 1996 Intraoperative nursing care as experienced by surgical patients. American Operating Room Nurses' Journal 63 (2) 435 - 442

Howat G, Weiters M, Sames M and McLaren A 2006 A pilot study of day case and short-stay thyroid surgery Journal of One Day Surgery 16 (1) 9 - 12

Jacquet E, Puche $P$, Alahyane J, et al. 2006 Evaluation of inguinal hernia in ambulatory surgery: A prospective monocentric study on 1009 inguinal hernia Ambulatory Surgery 12 (4) 167 - 171

Jakobsen VH and Fagermoen MS 2005 Environmental factors in the operating theatre and their impact on patients' preoperative anxiety [Norwegian] Tidsskrift For Sykepleieforskning 7 (4) 4 - 17

Johansson K, Nuutila L, Virtanen H, Katajisto J and Salanterä S 2005 Pre-operative education for orthopaedic patients: Systematic review Journal of Advanced Nursing 50 (2) 212 - 223

Kennedy BW, Thorp JM, Fitch W and Millar K 1992 The theatre environment and the awake patient Journal of Obstetrics and Gynaecology 12407 - 411

Kindler CH, Szirt L, Sommer D, Hausler R and Langewitz W 2005 A quantitative analysis of anaesthetist-patient communication during the pre-operative visit Anaesthesia 60 (1) 53 - 59

Koscielniak-Nielsen ZJ, Rotboll-Nielsen P and Rassmussen H 2002 Patients' experiences with multiple stimulation axillary block for fast-track ambulatory hand surgery. Acta Anaesthesiologica Scandinavica. 46 (7) $789-793$

Lack JA, Rollin A-M, Thoms G, White L and Williamson C 2003 Raising the Standard: Information for patients RCoA and AAGBI, London 
Lee A, Chui PT and Gin T 2003 Educating patients about anesthesia: A systematic review of randomized controlled trials of media-based interventions Anesthesia and Analgesia 96 (5) 1424 1431

Lee A and Gin T 2005 Educating patients about anaesthesia: effect of various modes on patients' knowledge, anxiety and satisfaction. Current Opinion in Anaesthesiology 18 (2) 205 - 208

Lehrner J, Eckersberger C, Walla P, Pötsch G and L. Deecke L 2000 Ambient odor of orange in a dental office reduces anxiety and improves mood in female patients Physiology and Behavior 71 (1 2) $83-86$

Leinonen T and Leino-Kilpi H 1999 Review: Research in peri-operative nursing care Journal of Clinical Nursing 8 (2) 123 - 138

Leinonen T, Leino-Kilpi H and Jouko K 1996 The quality of intra-operative nursing care: The patient's perspective Journal of Advanced Nursing 24 (4) 843 - 852

Lithner M and Zilling T 2000 Pre and postoperative information needs. Patient Education and Counseling 40 (1) 29 - 37

Lorenz SG 2007 The potential of the patient room to promote healing and well-being in patients and nurses: An integrative review of the research Holistic Nursing Practice 21 (5) 263 - 277

Marran J 2005 Psychological needs of patients in the peri-operative environment. Journal of Operating Department Practice 2 (5) 10 - 14

Matthey PW, Finegan BA and Finucane BT 2004 The public's fears about and perceptions of regional anesthesia Regional Anesthesia and Pain Medicine 29 (2) 96 - 101

Mauleon AL, Palo-Bengtsson L and Ekman S-L 2007 Patients experiencing local anaesthesia and hip surgery Journal of Clinical Nursing 16 (5) 892 - 899

McCarthy RJ, Trigg R, John C, Gough MJ and Horrocks M 2004 Patient satisfaction for carotid endarterectomy performed under local anaesthesia. European Journal of Vascular and Endovascular Surgery 27 (6) 654 - 659

McKenna D 1997 A focus on the five senses of the day surgery patient: a quality assurance initiative Ambulatory Surgery 5 (2) 61 - 65

Mitchell MJ 1997 Patients` perceptions of pre-operative preparation for day surgery Journal of Advanced Nursing 26 (2) 356 - 363

Mitchell MJ 2000 Anxiety management: A distinct nursing role in day surgery Ambulatory Surgery 8 (3) 119 - 128

Mitchell MJ 2005 Anxiety Management in Adult Day Surgery: A Nursing Perspective Whurr, London

Mitchell MJ 2006 Nursing knowledge and the expansion of day surgery in the United Kingdom Ambulatory Surgery 12 (3) 131 - 138

Mitchell MJ 2008 Conscious surgery: Influence of the environment on patient anxiety Journal of Advanced Nursing

Nijkamp MD, Ruiter RAC, Roeling M, et al. 2002 Factors related to fear in patients undergoing cataract surgery: A qualitative study focusing on factors associated with fear and reassurance among patients who need to undergo cataract surgery Patient Education and Counseling 47 (3) 265 - 272

Papanikolaou MN, Voulgari A, Lykouras L, Arvabitis Y, Christodoulou GN and Danou-Roussaki A 1994 Psychological factors influencing the surgical patients' consent to regional anaesthesia Acta Anaesthesiologica Scandinavica 38 (6) 607 - 611

Parroy S, Thoms G and Williamson C 2003 The practicalities of developing patient information. In J. A. Lack, A.-M. Rollin, G. Thoms, L. White and C. Williamson (eds) Raising the Standard: Information for patients RCoA and AAGBI, London

Raeder J 2006 Anaesthetic techniques for ambulatory surgery. In P. Lemos, P. Jarret and B. Philip (eds) Day Surgery: Development and Practice International Association of Ambulatory Surgery ( $p$. 185 - 208), Porto

Rees S and Tagoe M 2002 The efficacy and tolerance of local anaesthesia without sedation for foot surgery. Foot 12 (3) 188 - 192

Royal College of Anaesthetists and Association of Anaesthetists Great Britain and Ireland 2003 Anaesthesia explained: Information for patients, relatives and friends. RCA and AAGBI, London.

Rudolfsson G, Hallberg LRM, Ringsberg KC and von Post I 2003 The nurse has time for me: The perioperative dialogue from the perspective of patients Journal of Advanced Perioperative Care 1 (3) $77-84$ 
Rudolfsson G, von Post I and Eriksson K 2007 The perioperative dialogue: Holistic nursing in practice Holistic Nursing Practice 21 (6) 292 - 298

Shevde K and Panagopoulos G 1991 A survey of 800 patients' knowledge, attitudes, and concerns regarding anesthesia Anesthesia and Analgesia 73 (2) 190 - 198

Stirling L 2006 Reduction and management of perioperative anxiety British Journal of Nursing 15 (7) $359-361$

Stirling L, Raab G, Alder EM and Robertson R 2007 Randomized trial of essential oils to reduce perioperative patient anxiety: Feasibility study Journal of Advanced Nursing 60 (5) 494 - 501

Ternisien E, Gentili ME, Orain C, Wodey E and Ecoffey C 2006 Blocks at the wrist using nerve stimulation for ambulatory hand surgery Ambulatory Surgery 12 (4) 187 - 190

Tong D, Chung $\mathrm{F}$ and Wong $\mathrm{D} 1997$ Predictive factors in global and anesthesia satisfaction in ambulatory surgical patients. Anesthesiology 87 (4) 856 - 864

Ward C, Varvinski A and Montgomery J 2007 Patients' choice of induction method: Do patients prefer being given a choice of their induction method? Journal of One-Day Surgery 17 (2) 33 - 36

Weidmann C and Grundy P 2008 Day case awake craniotomy for tumour resection Journal of OneDay Surgery 18 (2) 45 - 47

Whittle IR, Midgley S, Georges H, Pringle AM and Taylor R 2005 Patient perceptions of "awake" brain tumour surgery Acta Neurochirurgica. 147 (3) 275 - 277

Wilmore DW 2002 From Cuthbertson to fast-track surgery: 70 years of progress in reducing stress in surgical patients Annals of Surgery 236 (5) 643 - 648

Yung PMB, Kam SC, Lau BWK and Chan TMF 2003 The effect of music in managing preoperative stress for Chinese surgical patients in the operating room holding area: A controlled trial. International Journal of Stress Management. 10 (1) 64 - 74

Zanchetta $C$ and Bernstein M 2004 The nursing role in patient education regarding outpatient neurosurgical procedures. AXON 25 (4) $18-21$ 